\title{
Coastal sediment dynamics, ecology and detection of coral reef macroalgae from AVIRIS-NG
}

\author{
R. Ratheesh ${ }^{1, *}$, Nandini Ray Chaudhury ${ }^{1}$, Preeti Rajput ${ }^{1}$, Mohit Arora ${ }^{1}$, \\ Ashwin Gujrati ${ }^{1}$, S. V. V. Arunkumar', Ateeth Shetty ${ }^{2}$, Rakesh Baral ${ }^{3}$, \\ Rakesh Patel ${ }^{4}$, Devanshi Joshi ${ }^{4}$, Harshad Patel ${ }^{4}$, Bharat Pathak ${ }^{4}$, K. S. Jayappa ${ }^{2}$, \\ R. N. Samal ${ }^{3}$ and A. S. Rajawat ${ }^{1}$ \\ ${ }^{1}$ Space Applications Centre, Indian Space Research Organisation, Ahmedabad 380 015, India \\ ${ }^{2}$ Mangalore University, Mangalagangorti, Mangaluru 574 199, India \\ ${ }^{3}$ Chilika Development Authority, Bhubaneswar 751 014, India \\ ${ }^{4}$ Gujarat Ecological Education and Research Foundation, Gandhinagar 382 007, India
}

This article highlights major scientific outcomes of the studies carried out using Airborne Visible/Infrared Imaging Spectrometer-Next Generation (AVIRIS-NG) airborne data over the coastal regions of Mangaluru, Gulf of Kachchh (GoK) and Chilika lagoon. Various hyperspectral remote sensing techniques involving bio-optical models and spectral classification algorithms are used to achieve different objectives related to coastal ecosystem monitoring. AVIRIS-NG airborne data are used to estimate particle size of suspended solids along the coastal waters of Mangaluru using an analytical optical model. The spatial distribution of particle size of the suspended solids in the coastal waters is brought out, while along the coastal land of Mangaluru, the beaches are classified based on uniform sediment characteristics using spectral matching algorithm. AVIRIS-NG data for Pirotan reef in GoK is analysed and species-level identification of the dominant brown macroalgae is carried out. Species-level distribution of brown macroalgae is mapped and used to study the microhabitat preference of different species. At Chilika lagoon, the AVIRIS-NG data are analysed to map the abundance of submerged seagrass using bio-optical model, which provides vital information to the coastal management community. The study asserts the importance of hyperspectral data and various advanced data analysis techniques related to the estimation of geophysical parameters of the coastal waters and monitoring the vital coastal ecosystems.

Keywords: Brown macroalgae, coastal regions, suspended sediment properties, submerged seagrass.

\section{Introduction}

CRITICAL monitoring of coastal regions is important as it addresses different aspects of environmental dynamics

\footnotetext{
*For correspondence. (e-mail: ratheeshr@sac.isro.gov.in)
}

pertaining to the combined impact of anthropogenic, natural and climatic processes. Coastal areas are characterized by complex interactions between land and water through exchange of physical and biogeochemical properties at different scales, which make their monitoring difficult. Due to these complex interactions, satellite observations using multispectral remote sensing often fail to decipher the coastal characteristics. Imaging spectroscopy, also known as hyperspectral imaging, has evolved to become one of the promising and challenging techniques in remote sensing. The contiguous observations in a selected spectral range, with narrow bandwidth have made hyperspectral remote sensing expand its capabilities over multispectral imaging ${ }^{1}$.

The suspended solids in the coastal waters play a vital role in the biogeochemical cycles and their size distribution is the key to understanding material exchanges between land and ocean ${ }^{2}$. The horizontal and vertical fluxes of materials within the water column are determined by particle size and particle size also influences the penetration of light through water. Determination of particle size of suspended solids is confined by using field instruments like particle size analyser. However, Zhang et al. ${ }^{3}$ have brought out a novel method to estimate particle size from in situ observed remote sensing reflectance. The present study have estimated particle size of suspended solids using remote sensing reflectance from Airborne Visible/ Infrared Imaging Spectrometer-Next Generation (AVIRIS-NG) data. The material exchange between land and ocean cannot be comprehended until the spatial variability in the sediment distribution along the coastal beaches is understood ${ }^{4}$. Mapping the spatial variability of the sediment distribution provides unique and valuable information for identifying sediment cells of unique characteristics and deciphering the local sediment transport dynamics.

The coastal zones are ecologically rich and bestowed with vital coastal ecosystems like coral reefs and 
mangroves which are sensitive to climate change. As an underwater remote sensing target, coral reefs appear as mosaics of diverse substrates or bottom types when viewed from space. Spectral nature of the remotely sensed data is recognized as the basic link between coral reef substrates and remotely sensed images ${ }^{5}$. Imaging spectrometry remains a promising field for coral reef remote sensing, especially for substrate detection, characterization and mapping. Benthic macroalgae are primary producers in a reef ecosystem and perform vital ecological functions like reef structure stabilization, production of tropical sands, nutrient retention and recycling, primary productivity and trophic support ${ }^{6}$. Brown macroalgae (class: Phaeophyceae) are almost exclusively marine and well represented in coral reef ecosystems, particularly in back-reef areas ${ }^{7}$. Among the tropical brown algae, Sargassaceae family members represent one of the complex and structurally robust forms. They are predominant in high-energy reef zones and often form small-scale forests up to several metres high that provide high biomass, habitat and shelter for numerous fishes and reef invertebrates $^{7}$. In India, Sargassaceae species are used for alginate and liquid seaweed fertilizer production ${ }^{8}$. In case of Indian coral reefs, high-resolution multispectral sensors have been successful only to map reef macroalgae as a broad ecological community ${ }^{9,10}$, but classification into different pigment groups thus far has not been attempted.

Similarly, in shallow-water lagoons, the submerged seagrass plays an important role in coastal ecosystems forming as food source ${ }^{11}$ and habitat for many organisms. It also influences the nutrient cycle and limits the resuspension of bottom sediments ${ }^{12}$. The seagrass meadows are sensitive to human impacts, and their monitoring and management are necessary for a healthy coastal environment. Remote sensing data have been extensively used to map the submerged seagrass, owing the ability of visible spectrum to penetrate the water body. Pu et al. ${ }^{13}$ have highlighted the advantages of hyperspectral data over multi-spectral data in mapping seagrass habitat. Separation of additional water column reflectance due to the inherent optical properties (IOP) is the major limitation while using remote sensing data ${ }^{14}$. In Chilika lagoon, substrates on which seagrass meadows are found, are located in more turbid waters with coloured dissolved organic matter $(\mathrm{CDOM})^{15}$. The advanced hyperspectral image processing techniques like spectral inversion procedures can be used for simultaneous estimation of water column parameters, water column depth and the abundancy of different substrate types ${ }^{16}$. The spectral inversion model is based on matching spectral measurements using bio-optical models through inversion techniques. The present study describes the application of AVIRISNG airborne data collected over selected coastal regions in estimating the above-mentioned coastal geophysical parameters and ecosystem monitoring.

\section{Study area}

The Mangaluru coast is located in the southwest of the Indian peninsula $\left(12^{\circ} 47.4^{\prime} \mathrm{N}\right.$ to $13^{\circ} 16.2^{\prime} \mathrm{N}, 74^{\circ} 37.2^{\prime} \mathrm{E}$ to $74^{\circ} 56.4^{\prime} \mathrm{E}$; Figure 1). It is a wave-dominated coast with complex geomorphology. The waves from southwest, west and northwest directions play an important role in setting up of long shore currents either directed towards the north or south with varying intensities, which in turn are responsible for the littoral drift in northerly or southerly direction in varying quantities ${ }^{17}$. Various coastal landforms along the Mangaluru coast include spits, sand bars, coastal dunes, beach ridges, wetlands, tidal flats, shoals and flood plains. The Mangaluru coast is subjected to severe coastal erosion along its southern parts in the Netravati River mouth, while alternate accreting and eroding sectors are observed to its north ${ }^{18}$.

The Gulf of Kachchh (GoK) $\left(22^{\circ} 15^{\prime}-23^{\circ} 40^{\prime} \mathrm{N} ; 68^{\circ} 20^{\prime}-\right.$ $70^{\circ} 40^{\prime} \mathrm{E}$ ) is an east-west-oriented, macro-tidal region in the west coast of India. The variability in tidal currents contributes significantly to the sediment dynamics of $\mathrm{GoK}^{19}$. The complex system of GoK is composed of fragile marine ecosystem where, amid the tidal channels, are small shoals and coral islands, controlling the tidal current patterns and sediment dynamics within the Gulf ${ }^{20}$. Pirotan reef $\left(22^{\circ} 34.68^{\prime}-22^{\circ} 37.1^{\prime} \mathrm{N}, 69^{\circ} 55.9^{\prime}-69^{\circ} 58.95^{\prime} \mathrm{E}\right)$ is a core part of the Gulf of Kachchh Marine National Park (MNP), situated in the $\mathrm{GoK}^{21}$. Pirotan is a fringing type of reef with a mangrove island in its core. Pirotan Island consists of a unique assemblage of ecologically sensitive coastal ecosystems: mangroves, coral reefs, seagrasses, macroalgal beds and low-tide beaches.

Chilika lagoon $\left(19^{\circ} 18^{\prime}-19^{\circ} 58.8^{\prime} \mathrm{N} ; \quad 84^{\circ} 56.4^{\prime}-\right.$ $85^{\circ} 46.2^{\prime} \mathrm{E}$ ), the largest brackish water lagoon of India, is situated along the east coast. The lagoon is separated from the Bay of Bengal by a sand spit, where the spit is constantly changing. The sand bar is reported to be widening and the position of the mouth is shifting towards the northeast ${ }^{22}$. Chilika lagoon is one of the hotspots of biodiversity in the country and is inhabited by rare, vulnerable and endangered species. Chilika is also famous as a wintering ground for migratory birds and this highly productive eco-system is rich with fishery resources that sustain the livelihood of natives around the lagoon. The major ecological issues faced along the Chilika lagoon are weak exchange between the sea and the lagoon, macrophyte infestation, eutrophication, loss of biodiversity, decline in fish productivity and growth of invasive species $^{23}$.

\section{Materials and methods}

AVIRIS-NG sensor developed by Jet Propulsion Lab (JPL), National Aeronautics and Space Administration (NASA) is a state-of-the-art imaging spectrometer and 


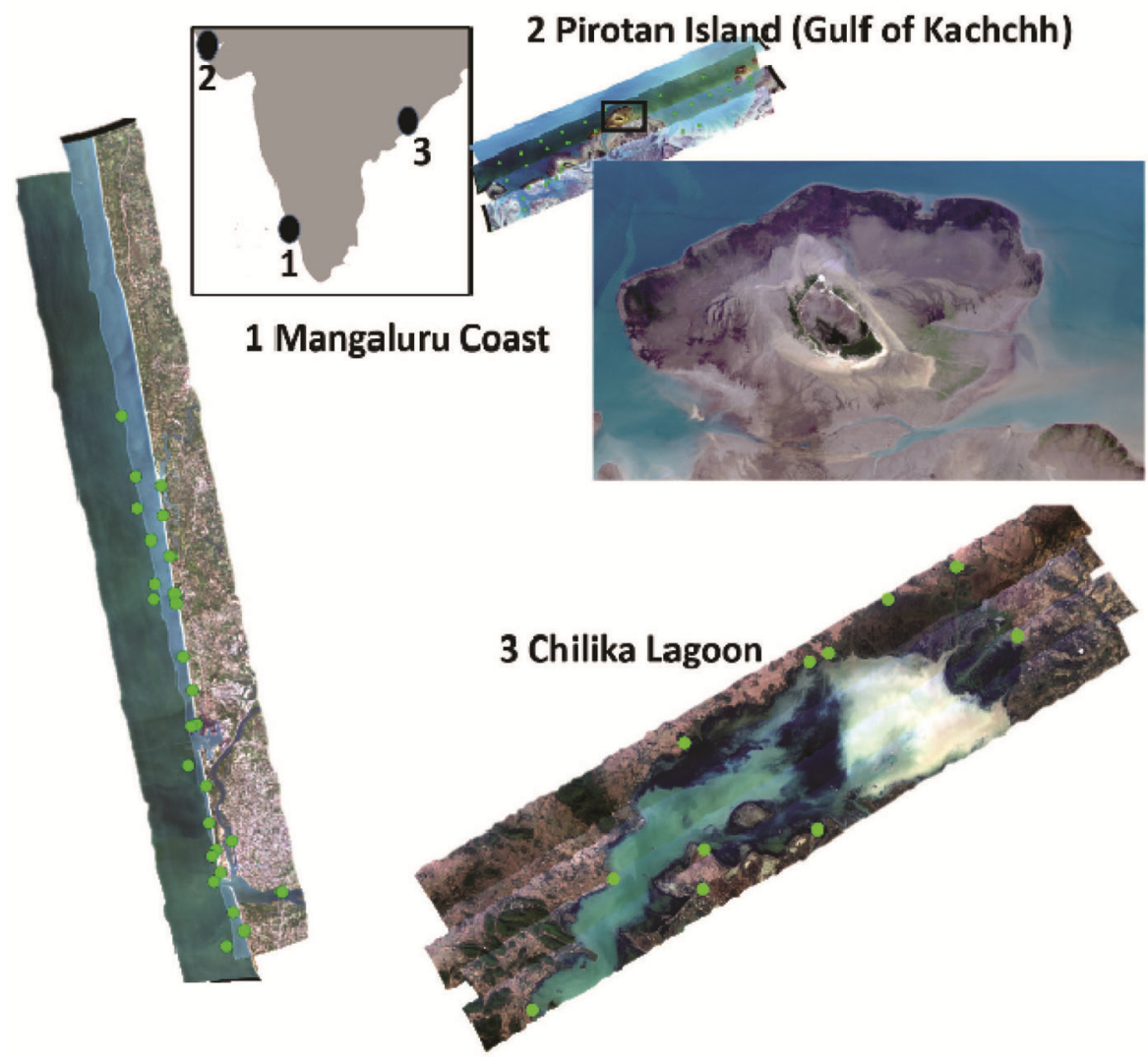

Figure 1. True colour composites of the study areas along with in situ locations: (1) Mangaluru coast; (2) Pirotan Island (Gulf of Kachchh); (3) Chilika lagoon.

has 430 narrow contiguous spectral bands in the visible and near infrared (VNIR) and short wave infrared (SWIR) regions in the wavelength range of 380-2510 nm with $5 \mathrm{~nm}$ interval. The instrument has a field of view (FOV) of $34^{\circ}$ and an instantaneous field of view (IFOV) of $1 \mathrm{mrad}$. The ground sampling distance (GSD) varies from 4 to $8 \mathrm{~m}$ from an effective flight altitude of $4-8 \mathrm{~km}$ with a swath of $4-6 \mathrm{~km}$.

Low-tide exposure of Pirotan reef and adjoining tidal mudflats at GoK was acquired by airborne AVIRIS-NG sensor on 14 February 2016. Sortie along the Mangaluru coast was carried out on 31 December 2015, while three days, i.e. 26-28 December 2015 were taken to cover the entire Chilika lagoon. Flight synchronous field campaigns were carried out for each study area and the synchronous spectral data were collected using HR1024 full-range spectrometer and Analytical Spectral Devices (ASD) Field SpecPro spectroradiometers.

Particle size of the suspended sediments, defined as $d_{50}$, along the coastal waters of Mangaluru was estimated from the water-leaving radiance observed from airborne AVIRIS-NG, which was then compared with in situ observations. Water samples were collected along the Mangaluru coast at the locations shown in Figure 1. Water samples were analysed in the laboratory to estimate total suspended solids (TSS) conventionally, where
11 of water was filtered and the matter retained on $<0.45 \mu \mathrm{m}$ optipure fibre filter paper was considered as TSS. After estimating TSS, the filter paper and samples were separated out through an ultrasonic bath. Calcium carbonate and other organic matter were removed and the sample was analysed using a laser diffraction particle size analyser to estimate particle size distribution of the samples.

Zhang et al. ${ }^{3}$ have retrieved particle size distribution of suspended sediments by inverting the following equation, which represents the relationship between inherent optical properties of water and reflectance

$$
\begin{aligned}
& R_{\mathrm{rs}(\lambda)}=f \frac{b_{\mathrm{b}(\lambda)}}{a_{\lambda}+b_{\mathrm{b}(\lambda)}}, \\
& a_{(\lambda)}=a_{\mathrm{w}(\lambda)}+a_{\mathrm{s}(\lambda)}+a_{y(\lambda)}+a_{\mathrm{ph}(\lambda)}
\end{aligned}
$$

and

$$
b_{\mathrm{b}(\lambda)}=b_{\mathrm{w}(\lambda)}+b_{\mathrm{s}(\lambda)}+b_{\mathrm{ph}(\lambda)},
$$

where $R_{\mathrm{rs}(\lambda)}$ is the remote sensing reflectance, $f$ a proportionality factor and considered to be 0.33 in this study, $b_{\mathrm{b}(\lambda)}$ the total backscattering coefficient and $a_{\lambda}$ is the total absorption coefficient, which depends on the coefficient 
of pure water (w), phytoplankton ( $\mathrm{ph})$, suspended sediment (s) and CDOM (y).

For a medium containing particles with particle size distribution (PSD) described as $N(D)$, with number of sediment size classes ' $n$ ', the volumetric coefficient of light absorption and backscattering coefficient can be given as

$$
\begin{aligned}
& a_{\mathrm{s}(\lambda)}=\sum_{i=n}^{n} N\left(D_{i}\right) \frac{Q_{\mathrm{as}(\lambda, i)} \pi D_{i}^{2}}{4} \Delta D_{i} \\
& b_{\mathrm{bs}(\lambda)}=\sum_{i=n}^{n} N\left(D_{i}\right) \frac{Q_{\mathrm{bs}(\lambda, i)} \pi D_{i}^{2}}{4} \Delta D_{i},
\end{aligned}
$$

where $a_{\mathrm{s}(\lambda)}$ and $b_{\mathrm{bs}(\lambda)}$ are the absorption and backscattering coefficients of suspended sediments, and $Q_{\mathrm{as}(\lambda)}$ and $Q_{\mathrm{bs}(\lambda, i)}$ are the efficiency factor of the sediments in suspension, related to the category of the mineral in the sediment. We have set the total number of sediment size classes to 30 within a size range from 55 to $195 \mu \mathrm{m}$ at an increment of $5 \mu \mathrm{m}$, which falls within the category of silts and fine sands. Using eqs (2) and (3), eq. (1) can be rearranged as

$$
\begin{aligned}
& {\left[\begin{array}{ll}
\left(\left(0.33-R_{\lambda_{1}}\right) Q_{\mathrm{b} 1}-R_{\lambda_{1}} Q_{\mathrm{a} 1}\right) \Delta D & \cdots \\
\cdots & \cdots \\
\left(\left(0.33-R_{\lambda_{n}}\right) Q_{\mathrm{b} 1}-R_{\lambda_{n}} Q_{\mathrm{a} 1}\right) \Delta D & \cdots
\end{array}\right.} \\
& \left.\begin{array}{c}
\left(\left(0.33-R_{\lambda_{1}}\right) Q_{\mathrm{b} n}-R_{\lambda_{1}} Q_{\mathrm{a} n}\right) \Delta D \\
\cdots \\
\left(\left(0.33-R_{\lambda_{n}}\right) Q_{\mathrm{b} n}-R_{\lambda_{n}} Q_{\mathrm{a} n}\right) \Delta D
\end{array}\right]\left[\begin{array}{c}
N D(1) \\
\cdots \\
N(D n)
\end{array}\right] \\
& =\left[\begin{array}{c}
R_{\lambda 1}\left(a_{\mathrm{w}(\lambda 1)}+a_{y(\lambda 1)}+a_{\mathrm{ph}(\lambda 1)}+b_{\mathrm{w}(\lambda 1)}+b_{\mathrm{ph}(\lambda 1)}\right) \\
\ldots \\
R_{\lambda n}\left(a_{\mathrm{w}(\lambda n)}+a_{y(\lambda n)}+a_{\mathrm{ph}(\lambda n)}+b_{\mathrm{w}(\lambda n)}+b_{\mathrm{ph}(\lambda n)}\right)
\end{array}\right. \\
& \left.\begin{array}{l}
-0.33\left(b_{\mathrm{w}(\lambda 1)}+b_{\mathrm{ph}(\lambda 1)}\right) \\
-0.33\left(b_{\mathrm{w}(\lambda n)}+b_{\mathrm{ph}(\lambda n)}\right)
\end{array}\right],
\end{aligned}
$$

where

$$
\frac{Q_{\mathrm{bs}(\lambda, i)} \pi D_{i}^{2}}{4}=Q_{\mathrm{b} i} \text { and } \frac{Q_{\mathrm{as}(\lambda, i)} \pi D_{i}^{2}}{4}=Q_{\mathrm{a} i} .
$$

For detailed derivation, refer to Zhang et al. ${ }^{3}$. Equation (4) is now in the form A.x = B, which can be solved by applying non-negative linear square algorithm (NNLS). Remote sensing reflectance spanning the wavelength range $500-650 \mathrm{~nm}(n=30)$ from the atmospherically cor- rected AVIRIS-NG image at 39 sites along the Mangaluru coast was used to estimate sediment size.

Spectral angle mapper (SAM)-based classification was carried out on JPL-processed level-2 reflectance data of AVIRIS-NG to classify the beaches of Mangaluru coast based on unique sediment properties. Fieldcollected ASD spectra of different beaches along the Mangaluru coast were used as endmembers whose corresponding sediment samples were collected and analysed for their organic/carbonate content and sediment size parameters.

AVIRIS-NG JPL-processed level-2 reflectance data was used to detect and map the species-level distribution of brown macroalgae along coral reef regions of Pirotan reef. In the field, a shore-perpendicular GPS-tagged line intercept transect (LIT) was used for reef substrate sampling and for each target, minimum three in situ target radiance spectra were recorded. In the Pirotan reef, four sampling stations on the LIT belonged to macroalgae substrate. Among these, three stations belonged to Sargassaceae family of brown macroalgae. Three Sargassaceae species were identified on the field based on their morphological criteria and reproductive structures. SAM algorithm was used to map the distribution of Sargassaceae species ${ }^{24}$. A multi-radian approach was initially employed on AVIRIS-NG data to visualize the classified maps of Sargassaceae members on smaller spatial and spectral subsets $(430-1350 \mathrm{~nm})$ of the data. The final classified map of Sargassaceae species for the whole Pirotan reef was generated with a single threshold angle set to 0.1 radian.

Abundance map of bottom seagrass at Chilika lagoon was estimated using bio-optical model, BOMBER (BioOptical Model Based tool for Estimating water quality and bottom properties from Remote sensing images) by Giardino et $a .^{25}$. The spectral inversion technique in BOMBER deals with the water column correction through estimation of the optically active water column parameter. The software package makes use of biooptical models, through optimization techniques to retrieve concentration maps of water constituents, bottom depth and distributions of up to three different types of substrate. Water-leaving radiance estimated using inhouse developed atmospheric correction algorithm was utilized to estimate the seagrass abundance map.

\section{Results and discussion}

\section{Mangaluru coast}

Estimation of particle size: Remote sensing reflectance $\left(R_{\mathrm{rs}}\right)$ from the atmospherically corrected AVIRIS-NG airborne data was used to estimate the particle size of suspended solids of the Mangaluru coastal waters. $R_{\mathrm{rs}}$ was extracted from 39 stations located along 13 transects, 
which are placed perpendicular to the coast (Figure $2 a$ ). About 30 sediment size classes within the range 65-190 $\mu \mathrm{m}$ and 30 spectral bands within the range 500$645 \mathrm{~nm}$ were used to solve eq. (4) by NNLS method.

Estimated sediment size for the stations is given in Table 1 (the three stations along the transect are represented as (i) to (iii) respectively, where (iii) is at the coast) and sediment size estimated for the corresponding locations using laser diffraction particle size analyser from in situ samples are given within brackets in the table.

The particle size estimated from in situ samples ranges from 65 to $123 \mu \mathrm{m}$, while that estimated from $R_{\mathrm{rs}}$ ranges from 75 to $130 \mu \mathrm{m}$. Even though the size range estimated from in situ samples and AVIRIS-NG overlaps, small disparity is observed for the estimated sediment sizes at specified locations. This can be attributed to the highly dynamic coastal waters and asynchronous in situ observations with respect to the AVIRIS-NG observations.

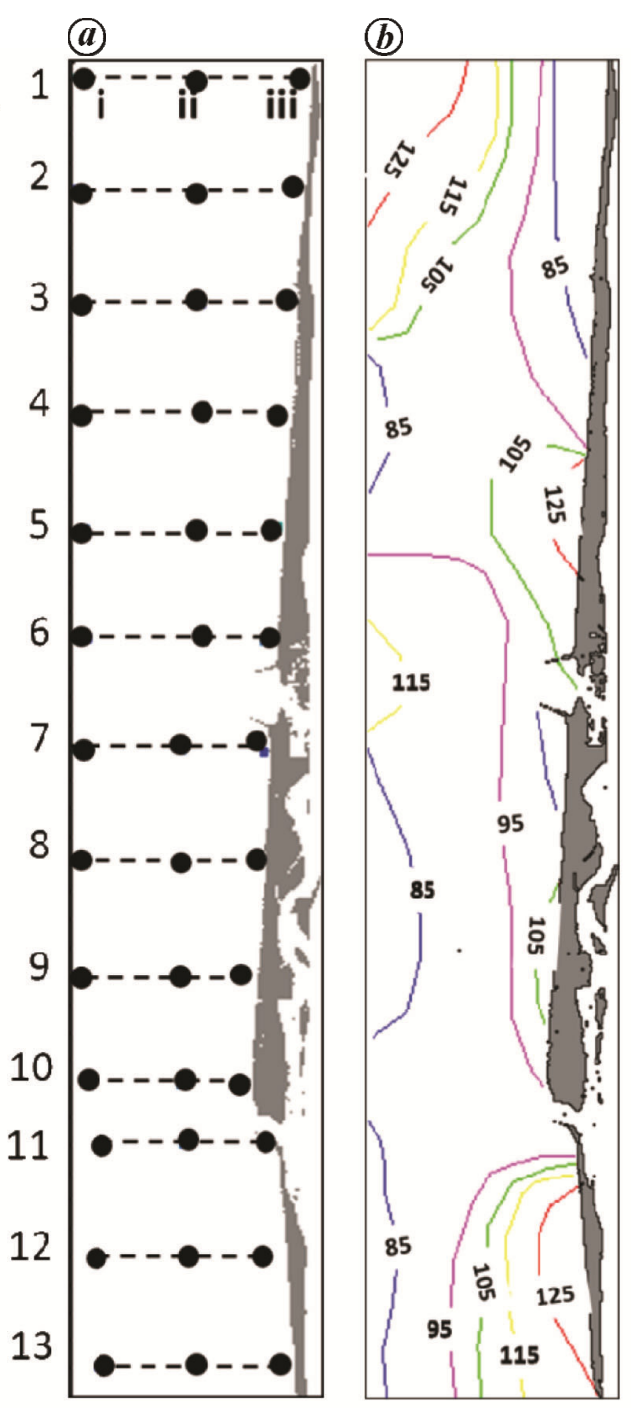

Figure 2. $\boldsymbol{a}$, Locations along which size of the suspended sediments is estimated. $\boldsymbol{b}$, Contour map of the size of suspended sediments $(\mu \mathrm{m})$.
Model-estimated sediment size was interpolated and contour map of the size of suspended solids was generated (Figure $2 b$ ). Larger sediment size, in general, is observed along the coast, while the size decreases away from the coast; but the trend is observed to be reversed along the northern region. The southern sector is prone to coastal erosion, where larger sediment size is expected along the near-coastal waters. Disposal of dredged material along the offshore region of the northern sector might be the possible reason for sediments with larger size at the offshore waters of the sector.

Beach classification: Beach sediments along the Mangaluru coast were collected and classified based on the sediment characteristics like organic/carbonate content, sediment size and sorting. Figure 3(i) shows the six classes of beach sediments, while Figure 3(ii) shows the corresponding in situ collected spectra. Classification was carried out using SAM algorithm, where in situ spectra were used as the endmembers. Figure 3(iii) shows distribution of the six classes of sediments along the Mangaluru coast. Very coarse and poorly sorted sediments are observed along the eroding beaches of the southern sector (box F, Figure 3(iii)), while depositional beaches (boxes $\mathrm{E}$ and $\mathrm{C})$ show very fine to fine sediments which are moderately well-sorted.

\section{Gulf of Kachchh}

Three species of Sargassaceae family were identified on field: (i) Sargassum tenerrimum J. G. Agardh, (ii) Sargassum prismaticum Chauhan and (iii) Cystoseira indica (Thivy \& Doshi) Mairh. The brown macroalgae species contain the auxiliary carotenoid pigment fucoxanthin, which absorbs a broader section of light in the blue and green regions of the spectrum. The characteristic triplepeaked reflectance appears for all the three species at

Table 1. Estimated sediment size $(\mu \mathrm{m})$ at different stations along the Mangaluru coast; sediment size $(\mu \mathrm{m})$ estimated using laser diffraction method for some of the overlapping stations are given within brackets

\begin{tabular}{rrcc}
\hline Station & i (Off) & ii (Middle) & iii (Coast) \\
\hline 1 & 130 & 120 & 75 \\
2 & 80 & 110 & 75 \\
3 & 105 & 70 & 75 \\
4 & 70 & $90(113.48)$ & 85 \\
5 & 100 & 95 & 130 \\
6 & 75 & 75 & $100(82.76)$ \\
7 & 120 & $90(79.24)$ & 75 \\
8 & 70 & 80 & 85 \\
9 & 75 & 75 & $95(123.09)$ \\
10 & 80 & 85 & 85 \\
11 & 75 & 80 & 120 \\
12 & 75 & 90 & 75 \\
13 & 85 & 85 & $65.23)$ \\
\hline
\end{tabular}



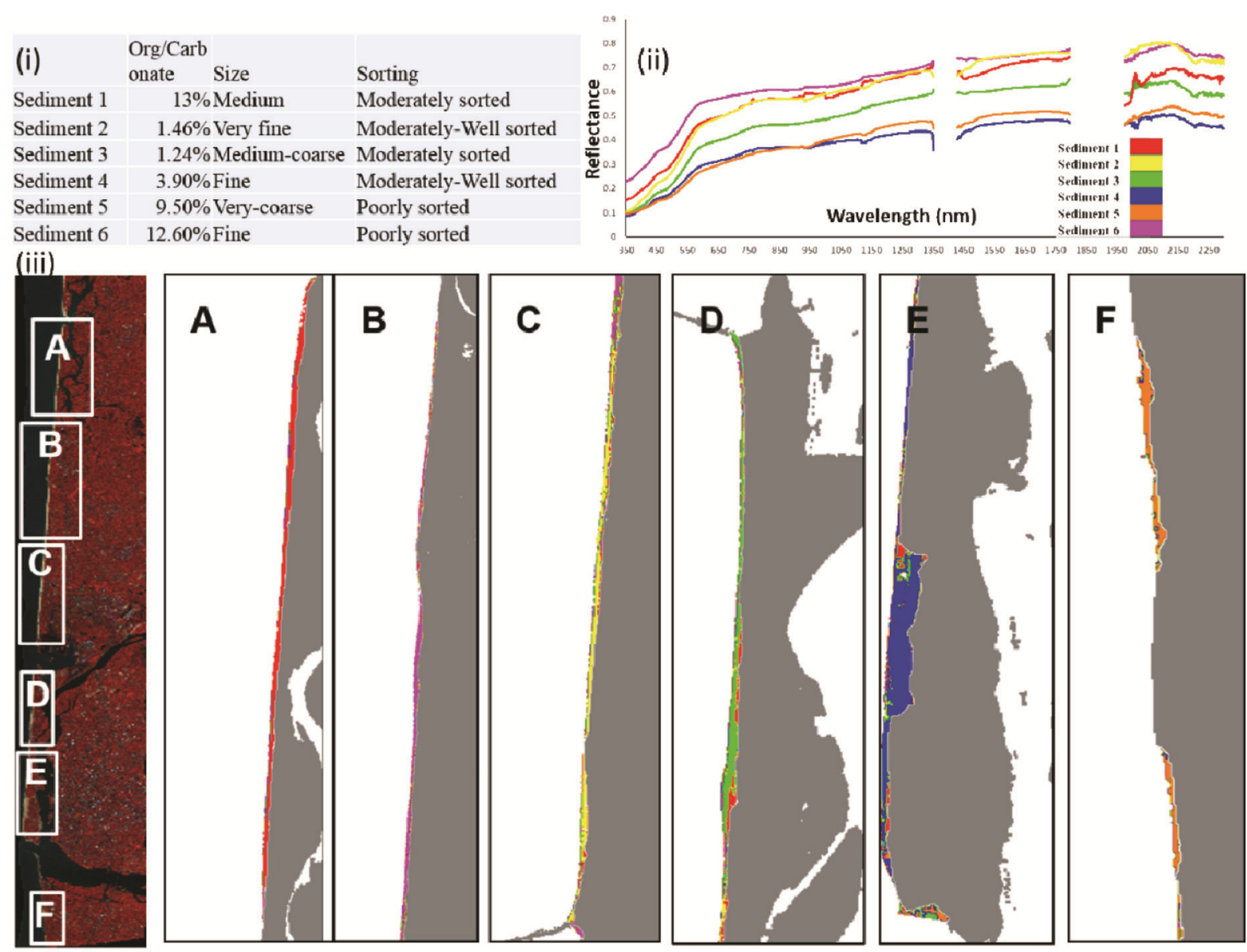

Figure 3. Classification of beaches along the Mangaluru coast based on uniform sediment characteristics: (i) six classes of beach sediments; (ii) in situ collected field spectra; (iii) classification results.

575,600 and $650 \mathrm{~nm}$ respectively, with the third peak recording a negative shift of the order of $4 \mathrm{~nm}$ at $646 \mathrm{~nm}$ (Figure $4 d$ ). The narrow chlorophyll absorption band is located within $670-680 \mathrm{~nm}$, followed by the characteristic red edge and relatively higher reflectance in the NIR region. The spectral convexity at 840 to $940 \mathrm{~nm}$ in the NIR region is indicative of the ripple effect of the marginal water column on the Sargassaceae species during the time of image acquisition ${ }^{26}$.

The mapped distribution shows the microhabitat preferences of Sargassaceae species (Figure $4 b$ ). S. tenerrimum and $S$. prismaticum inhabit the outer reef flat, while $C$. indica is found as an ubiquitous species inhabiting both outer and inner reef flats of the Pirotan reef. This is primarily due to the species preference of bottom substrate. $S$. tenerrimum and $S$. prismaticum generally occur in the reef zones with hard rocks, while $C$. indica prefers both hard and soft substrates like coralline stones and sand ${ }^{8}$.

Field-level validation exercise for the mapped brown macroalgae species in Pirotan reef was carried out during 3-5 February 2018, matching the best possible low-tide condition and seasonal abundance of Sargassaceae species. Sixty GPS-tagged ground-truth reference points were collected during the three-day campaign period, out of which 12 sample points could qualify to assess the accuracy of their mapped distribution and their habitat and substrate preferences. Among the 12 sample reference points, 10 (i.e. $83 \%$ of the points) belonged to the outer reef flat and recorded presence of $S$. prismaticum for 4 sample stations, $C$. indica for three sample stations while the remaining three stations showed three different Sargassaceae species combinations. One reference station showed all the three species; another had the combination of $S$. tenerrimum and $S$. prismaticum while yet another had the combination of $S$. prismaticum and $C$. indica. The remaining two out of the 12 sample reference points represented the inner reef flat and coincided with the presence of $C$. indica species only. Presence of $C$. indica in both the outer and inner reef flats and absence of $S$. tenerrimum and $S$. prismaticum in the inner reef flat conform to the inference drawn about their microhabitat preferences from the species distribution map based on AVIRIS-NG data. Substrate preference of these Sargassaceae species has earlier been catalogued by Jha et al. ${ }^{8}$.

Twelve sample reference points collected and qualified for field-level validation, for species-level distribution 


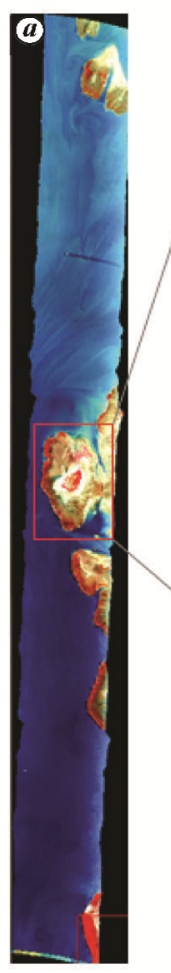

AVIRIS-NG strip over Pirotan Reef Flight Date: 14.02.2016

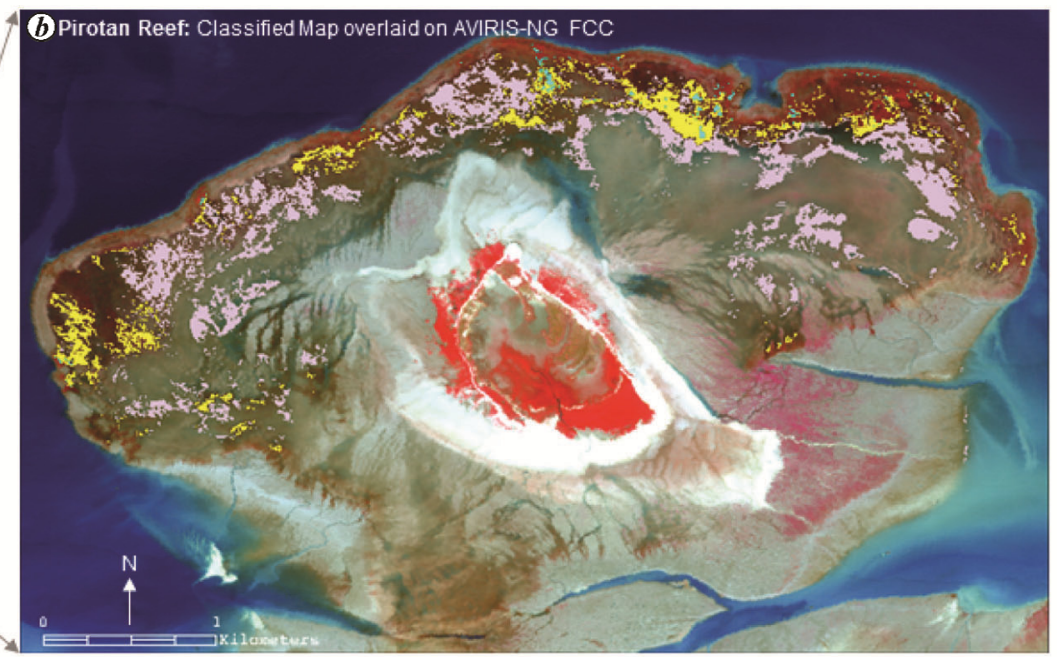

Classified Map Legend: Brown Algae Specie

End-member spectra of Sargassaceae species used in classification

0.14 Characteristic Triple Peaks
0.12 at 575,600 and $650 \mathrm{~nm}$

(d)

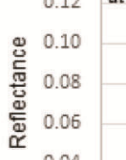

0.04

0.02

0.00

Cystoseira indica

- Sargassum sp.

(Sargassum prismaticum+

Sargassum tenerrimum)

Sargassum tenerrimum
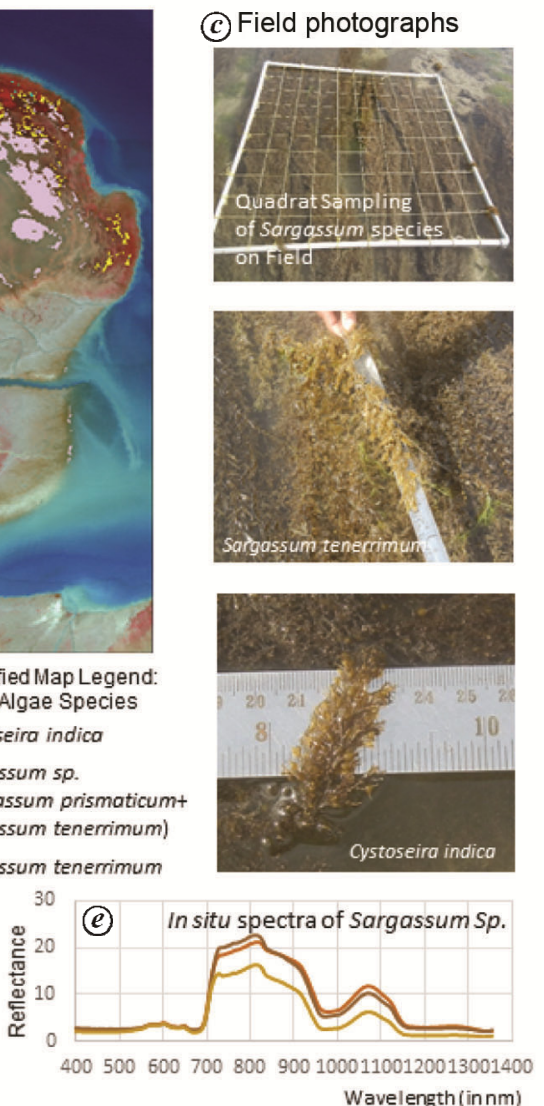

Figure 4. Spatial distribution of brown macroalgae belonging to the family Sargassaceae in Pirotan reef, Gulf of Kachchh using AVIRIS-NG data. $\boldsymbol{a}$, AVIRIS-NG strip dated 14 February 2016 over Pirotan reef; $\boldsymbol{b}$, Classified map of Sargassaceae species; $\boldsymbol{c}$, Field photographs of Sargassaceae species; $\boldsymbol{d}$, Endmember spectra of Sargassaceae species; $\boldsymbol{e}$, In situ reflectance spectra of Sargassaceae species.

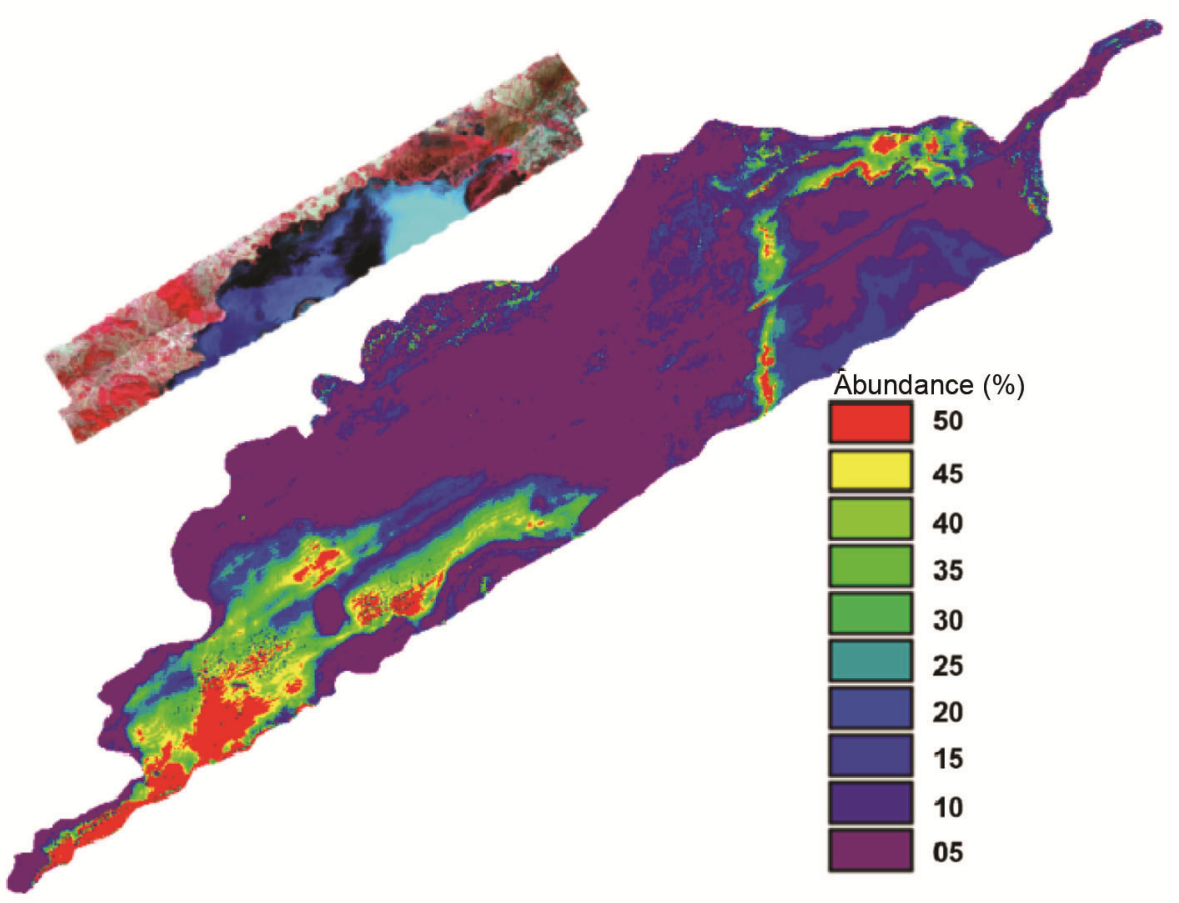

Figure 5. Abundance map of submerged seagrass estimated for Chilika lagoon. 
map for a reef with an area of $12.90 \mathrm{sq} . \mathrm{km}$ is definitely not sufficient ${ }^{8}$. In theory, validation of a habitat or discrete map requires minimum 50 reference points per thematic class for a mapped area less than $4000 \mathrm{~km}^{2}$ (ref. 27). This calls for a well-planned validation campaign with sufficient human and logistic resources for ensuring maximum sampling coverage during similar tidal and seasonal conditions as that of AVIRIS-NG imaging campaign.

\section{Chilika lagoon}

Atmospherically corrected AVIRIS-NG data of Chilika lagoon were used to map the abundance of submerged seagrass using bio-optical model (Figure 5), where the model was optimized with in situ collected spectra of the seagrass. Dominant seagrass species found in the lagoon are Halophila ovalis and Halodule uninervis ${ }^{22,28}$. Abundance was mostly along the southern sector of Chilika, which matches with the map generated by Geevarghese et $a l .{ }^{15}$ and Samal $^{22}$. Seagrass patch was also observed along the northern sector of the lagoon. Although the northern sector of Chilika is abundant in emergent invasive species like Pragmites karka, the presence of submerged seagrass here is still unreported.

\section{Conclusion}

This study highlights the potential applications of hyperspectral remote sensing data in achieving various objectives related to coastal ecosystem monitoring. One of the major outcomes discussed in the present study is the viable use of hyperspectral remote sensing data in estimating the particle size of suspended solids along the coastal waters of Mangalore. The derived map on the spatial distribution of the particle size, depicts the level of material exchange between land and ocean, where the coastal waters adjacent to the eroding beaches are observed to have larger particle size. The particle size map, in combination with the beach classification map will help to comprehend the energy level of the coastal environment. Classification of beach along the Mangaluru coast has shown the potential of hyperspectral data to distinguish beaches based on sediment cells with uniform sediment characteristics. Identification of different species of Sargassaceae family and mapping their spatial distribution using AVIRIS-NG data, have enabled in understanding the microhabitat preference, where $S$. tenerrimum and $S$. prismaticum inhabit along the reef zone with hard rock, while $C$. indica is observed along hard and soft substrates of coralline stones and sand. The study has also brought out the advantages of hyperspectral remote sensing in mapping abundance map of submerged seagrass, which is a vital activity in monitoring sensitive coastal ecosystems. Coastal regions are subjected to dynamic changes and are quite sensitive to external factors, which compels temporal monitoring of the coastal ecosystem. This asserts the importance of spaceborne hyperspectral observations with near specifications of airborne AVIRISNG to understand and estimate the coastal dynamics.

1. Goetz, A. F. H., Three decades of hyperspectral remote sensing of the Earth: a personal view. Remote Sensing Environ., 2009, 119, S5-S16.

2. Reynolds, R. A., Stramski, D., Wright, V. M. and Woźniak, S. B., Measurements and characterization of particle size distributions in coastal waters. J. Geophys. Res., 2010, 115, C08024.

3. Zhang, Y., Huang, Z., Chen, C., He, Y. and Jiang, T., Particle size distribution of river-suspended sediments determined by in situ measured remote-sensing reflectance. Appl. Opt., 2015, 54, 63676376.

4. Manzo, C., Valentini, E., Taramelli, A., Filipponi, F. and Disperati, Spectral characterization of coastal sediments using field spectral libraries, airborne hyperspectral images and topographic LiDAR data (FHyL). Int. J. Appl. Earth Obs., 2015, 36, 54-68.

5. Hochberg, E. J. and Atkinson, M. J., Capabilities of remote sensors to classify coral, algae and sand as pure and mixed spectra. Remote Sensing Environ., 2003, 85, 174-189.

6. Fong, P. and Paul, V. J., Coral reef algae. In Coral Reefs: An Ecosystem in Transition (eds Dubinsky, Z. and Stambler, N.), Springer, Dordrecht, The Netherlands, 2011, pp. 241-272.

7. Littler, M. M. and Littler, D. S., The nature of macroalgae and their interactions on reefs. Smithson. Contrib. Mar. Sci., 2013, 39, 187-198.

8. Jha, B., Reddy, C. R. K., Thakur, M. C. and Rao, U. M., Seaweeds of India, Springer, Dordrecht, The Netherlands, 2009, p. 215.

9. Navalgund, R. R. et al., Coral Reef Atlas of the World. Vol. 1. Central Indian Ocean, Space Applications Centre (ISRO), Ahmedabad, 2010, p. 282.

10. Bahuguna, A., Ray Chaudhury, N., Bhattji, N., Ajai and Navalgund, R. R., Spatial inventory and ecological status of coral reefs of the Central Indian Ocean using Resourcesat-1. Indian J. GeoMar. Sci., 2013, 42(6), 684-696.

11. Nõges, T., Luup, H. and Feldmann, T., Primary production of aquatic macrophytes and their epiphytes in two shallow lakes (Peipsi and Võrtsjärv) in Estonia. Aquat. Ecol., 2010, 44, 83-92.

12. Dekker, A. G. et al., Intercomparison of shallow water bathymetry, hydro-optics, and benthos mapping techniques in Australian and Caribbean coastal environments. Limnol. Oceanogr-Methods, 2011, 9, 396-425.

13. Pu, R., Bell, S., Levy, K. H. and Meyer, C., Mapping detailed seagrass habitats using satellite imagery. IGARSS, 2010.

14. Wicaksono, P. and Hafizt, M., Mapping seagrass from space: addressing the complexity of seagrass LAI mapping. Eur. J. Remote Sensing, 2013, 46, 18-39.

15. Geevarghese, G. A., Akhil, B., Magesh, G., Krishnan, P., Purvaja, R. and Ramesh, R., A comprehensive geospatial assessment of seagrass distribution in India. Ocean Coast. Manage., 2018, 159, $16-25$.

16. Odermatt, D., Gitelson, A., Brando, V. E. and Schaepman, M., Review of constituent retrieval in optically-deep and complex waters from satellite imagery. Remote Sensing Environ., 2012, 118, 116-126.

17. Jayappa, K. S., Vijaya Kumar, G. T. and Subrahmanya, K. R., Influence of coastal structures on beach morphology and shoreline in southern Karnataka, India. J. Coast. Res., 2003, 68, 874-884.

18. Shetty, A., Jayappa, K. S. and Mitra, D., Shoreline change analysis of Mangalore coast and morphometric analysis of NetravathiGurpur and Mulki-Pavanje spits. In International Conference on 
Water Resources, Coastal and Ocean Engineering, 2015, vol. 4, pp. $182-189$.

19. Ratheesh, R., Rajawat, A. S. and Ratheesh, S., Empirical orthogonal function analysis of suspended sediment concentration in Gulf of Kachchh, India, and its tidal influence. IEEE J. Sel. Topics Appl. Earth Observ. Remote Sensing, 2015, 8, 4562-4567.

20. Vethamony, P., Reddy, G. S., Babu, M. T., Desa, E. and Sudheesh, K., Tidal eddies in a semi-enclosed basin: a model study. Mar. Environ. Res., 2005, 59, 519-532.

21. Bhattji, N. S., Ray Chaudhury, N., Shah, D. G. and Desai, N., Sedimentation pattern in Pirotan reef, Gulf of Kachchh, India. J. Mar. Biol. Assoc. India, 2011, 53(1), 1-7.

22. Samal, R. N., Applications of RS \& GIS in wetland management: case study of Chilika lagoon. In User Interaction Meet Proceedings, US4, NRSC, India, 20-21 January 2014.

23. Panda, U. S., Mohanty, P. K. and Samal, R. N., Impact of tidal inlet and its geomorphological changes on lagoon environment: a numerical model study. Estuarine, Coast. Shelf Sci., 2013, 116, $29-40$.

24. Leiper, I. A., Phinn, S. R., Roelfsema, C. R., Joyce, K. E. and Dekker, A. G., Mapping coral reef benthos, substrates, and bathymetry, using Compact Airborne Spectrographic Imager (CASI) data. Remote Sensing, 2014, 6, 6423-6445.
25. Giardino, C., Candiani, G., Bresciani, M., Lee, Z., Gagliano, S. and Pepe, M., Bomber: a tool for estimating water quality and bottom properties from remote sensing images. Comput. Geosci., 2012, 45, 313-318.

26. Ray Chaudhury, N., Spectral characteristics of selected hermatypic corals from Gulf of Kachchh, India. Int. Arch. Photogramm., Remote Sensing Spatial Inf. Sci., 2012, XXXIX-B8, 333-338.

27. Roelfsema, C. M. and Phinn, S. R., Validation. In Coral Reef Remote Sensing: A Guide for Mapping, Monitoring and Management (eds Goodman, J. A., Purkis, S. J. and Phinn, S. R.), Springer, 2013, pp. 375-401.

28. Pati, M. P., Nayak, N. and Sharma, S. D., Studies on biomass of seagrass, seaweed and its associated fauna from Chilika lagoon. Int. J. Environ. Stud., 2014, 5, 423-431.

ACKNOWLEDGEMENTS. We thank Tapan Misra, Director, Space Applications Centre (SAC-ISRO), Ahmedabad for approving this paper for publication. We also thank Dr Raj Kumar, Deputy Director, EPSA, SAC for encouragement and support and the Marine National Park (MNP) authorities, Jamnagar, for permission to conduct the synchronous field campaign at Pirotan reef in GoK.

doi: $10.18520 / \mathrm{cs} / \mathrm{v} 116 / \mathrm{i} 7 / 1157-1165$ 